\title{
Considerations for Quality Improvement in Radiation Oncology Therapy for Patients with Uncomplicated Painful Bone Metastases
}

\author{
Anne M. Walling, MD, PhD, ${ }^{1-3}$ Phillip J. Beron, MD, Tania Kaprealian, MD, Patrick A. Kupelian, MD, \\ Neil S. Wenger, MD, MPH, ${ }^{2,3}$ Susan A. McCloskey, MD, Christopher R. King, MD, and Michael Steinberg, MD ${ }^{4}$ \\ The UCLA Radiation Oncology Quality Improvement for Patients with Painful Bone Metastases Panel
}

\begin{abstract}
Background: There is an increasing need for evidence-based efficiency in providing a growing amount of cancer care. One example of a quality gap is the use of multiple-fraction palliative radiation for patients with advanced cancer who have uncomplicated bone metastases; evidence suggests similar pain outcomes for treatment regimens with a lower burden of treatments.

Methods: During the first phase of quality improvement work, we used RAND/UCLA appropriateness methodology to understand how radiation oncologists at one academic medical center rate the appropriateness of different treatment regimens for painful uncomplicated bone metastases. We compared radiation oncologist appropriateness ratings for radiation treatments with radiation therapy provided by these oncologists to patients with painful bone metastases between July 2012 and June 2013.

Results: Appropriateness ratings showed that single-fraction (8 Gy) treatment (a low burden treatment) was consistently considered an appropriate option to treat a variety of uncomplicated bone metastases. The use of $>10$ fractions was consistently rated as inappropriate regardless of other factors. Eighty-one patients receiving radiation therapy for painful bone metastases during the study period had an available medical record for chart abstraction. Almost one-third of metastases were considered complicated because of a concern of spinal cord compression, a history of prior irradiation, or an associated pathological fracture. Among uncomplicated bone metastases, 25\% were treated with stereotactic body radiation treatment (SBRT). Among the 54 uncomplicated bone metastases treated with conformal radiation, only one was treated with single-fraction treatment and $32 \%$ were treated with greater than 10 fractions.

Conclusions: Treatment at the study site demonstrates room for improvement in providing low-burden radiation oncology treatments for patients with painful bone metastases. Choosing a radiation treatment schedule for patients with advanced cancer and painful bone metastases requires consideration of many medical and patient-centered factors. Our experience suggests that it will take more than the existence of guidelines to change practice in this area.
\end{abstract}

Keywords: advanced cancer; bone metastases; palliative care; quality of care; radiation oncology

\section{Introduction}

A LTHOUGH THE NEED for cancer care continues to rise, supporting evidence now exists for many specific care processes that can improve quality of life, particularly for advanced disease, while also reducing costs. ${ }^{1-7}$ Unfortunately, quality measurement studies identify performance gaps for such patient-centered care. ${ }^{8-10}$

One example of a quality gap is the use of multiplefraction palliative radiation for patients with advanced

\footnotetext{
${ }^{1}$ VA Greater Los Angeles Healthcare System, Los Angeles, California.

${ }^{2}$ Division of General Internal Medicine and Health Services Research, David Geffen School of Medicine at University of California, Los Angeles, California.

${ }^{3}$ RAND Health, Santa Monica, California.

${ }^{4}$ Department of Radiation Oncology, David Geffen School of Medicine at University of California, Los Angeles, California. Accepted November 28, 2016.
} 
Table 1. Subject Inclusion and Exclusion Criteria Among Studies Supporting 2011 ASTRO Guidelines for Radiation Treatment of Painful Bone Metastases

\begin{tabular}{|c|c|}
\hline Reference & Inclusion \\
\hline Jeremic et al. ${ }^{31}$ & $\begin{array}{l}\text { - Metastatic bone pain } \\
\text { - Proven malignant disease } \\
\text { - Pain history could be evaluated }\end{array}$ \\
\hline $\begin{array}{l}\text { Bone Pain Trial } \\
\text { Working } \\
\text { Party }^{32}\end{array}$ & $\begin{array}{l}\text { - Histological or cytological diagnosis of } \\
\text { malignant disease } \\
\text { - Age older than } 18 \text { years } \\
\text { - Clinical diagnosis of skeletal pain due to } \\
\text { malignant disease } \\
\text { - Patient's willingness to complete a pain } \\
\text { questionnaire for } 12 \text { months }\end{array}$ \\
\hline Roos et al. ${ }^{33}$ & $\begin{array}{l}\text { - Pathologically confirmed malignancy } \\
\text { - Plain X-ray or bone scan evidence of bone } \\
\text { metastasis at the index site. } \\
\text { - Pain or dysesthesia, predominantly of a } \\
\text { neuropathic nature } \\
\text { - Life expectancy of at least six weeks } \\
\text { - Able to complete the pain assessments }\end{array}$ \\
\hline Hartsell et al. ${ }^{34}$ & $\begin{array}{l}\text { - Age } 18 \text { years or older } \\
\text { - Histologically proven primary malignancy of } \\
\text { breast or prostate } \\
\text { - Radiographic evidence of bone metastasis, } \\
\text { pain corresponding to the area of bone } \\
\text { metastasis } \\
\text { - Karnofsky performance status of at least } 40 \text {, } \\
\text { and an estimated life expectancy of at least } \\
\text { three months. } \\
\text { - Eligible treatment sites were classified as } \\
\text { weight-bearing sites (i.e., pelvis [excluding } \\
\text { pubis], femur, tibia, sacrum, and/or sacroiliac } \\
\text { joints) or nonweight-bearing sites. } \\
\text { - Patients with as many as three separate sites of } \\
\text { painful metastases were eligible for the study. }\end{array}$ \\
\hline Kaasa et al. ${ }^{21}$ & $\begin{array}{l}\text { - Bone metastases resulting in clinically } \\
\text { important pain, judged by the physician and } \\
\text { the patient } \\
\text { - Biopsy- or cytology-proven malignant } \\
\text { disease, bone metastasis (at any site) verified } \\
\text { by bone X-ray, bone scan, computed } \\
\text { tomography, or magnetic resonance imaging } \\
\text { - Karnofsky performance status above } 40 \\
\text { - Patient able to complete the quality-of-life } \\
\text { assessment tools }\end{array}$ \\
\hline Foro et al. ${ }^{35}$ & - Age 18 years or older \\
\hline
\end{tabular}

- Metastasis within the distribution of the neuropathic pain (e.g., shaft of femur metastasis with L2 neuropathic pain)

- Prior radiotherapy to the index site

- Clinical or radiological evidence of compression of the spinal cord or cauda equina

- Pathological fracture of long bone(s) at index site

- Change in systemic therapy within six weeks before, or anticipated within four weeks after, commencing radiotherapy

- Neuropathic pain due primarily to extraskeletal tumor (e.g., presacral recurrence of rectal carcinoma)

- Painful area had received prior radiation therapy or palliative surgery, if there was a pathological fracture or an impending fracture of the treatment site, or if there was planned surgical fixation of the bone.

- Clinical or radiographic evidence of spinal cord or cauda equina compression and/or effacement

- Introduction of any systemic therapy (hormonal therapy, chemotherapy, immunotherapy, or systemic radioisotope therapy) within the 30 days before entry into the study

- Previous irradiation to the present symptom site

- Spinal cord compression

- Patients in need of bone surgery

- Life expectancy of less than six weeks

- Pain due to a pathological fracture or an impending fracture

- Clinical or radiographic evidence of spinal cord compression

- Pain at more than one site

- Prior radiotherapy at the same site

- Patients whose pain could not be assessed either because of an overall poor state of health or due to difficulties in applying the ordinal pain scale

- Estimated life expectancy of $<1$ month 
TABle 1. (CONTINUED)

\begin{tabular}{|c|c|c|}
\hline Reference & Inclusion & Exclusion \\
\hline Sande et al. ${ }^{36}$ & Same as Kaasa et al. ${ }^{21}$ & \\
\hline Nielsen et al. ${ }^{37}$ & $\begin{array}{l}\text { - Painful bone metastases localized to a single } \\
\text { region that could be encompassed within a } \\
\text { single radiation field } \\
\text { - Malignant disease was histopathologically or } \\
\text { cytologically confirmed, and the metastases } \\
\text { were radiologically verified. } \\
\text { - Patients able to complete a pain evaluation } \\
\text { form }\end{array}$ & $\begin{array}{l}\text { - Previous radiotherapy to the concerned region } \\
\text { - Pathological fractures except compression } \\
\text { fractures of the vertebral spinal column and } \\
\text { suspicion of spinal cord compression } \\
\text { - Life expectancy }<6 \text { weeks }\end{array}$ \\
\hline Steenland et al. ${ }^{38}$ & $\begin{array}{l}\text { - Patients with painful bone metastases from a } \\
\text { solid tumor } \\
\text { - Pain score of at least } 2 \text { on an 11-point scale } \\
\text { from 0 (no pain at all) to } 10 \text { (worst } \\
\text { imaginable pain) }\end{array}$ & $\begin{array}{l}\text { - Painful bone metastases not treatable in one } \\
\text { target volume } \\
\text { - Previously irradiated } \\
\text { - Pathological fracture that needed surgical } \\
\text { fixation or a spinal cord compression } \\
\text { - Patients with metastases of malignant } \\
\text { melanoma or renal cell carcinoma } \\
\text { - Patients with metastases in the cervical spine }\end{array}$ \\
\hline
\end{tabular}

ASTRO, American Society of Radiation Oncology.

cancer and painful bone metastasis, despite evidence suggesting similar pain outcomes for lower burden treatment regimens. This area for quality improvement is discussed in the Choosing Wisely Guidelines of both the American Society of Radiation Oncology (ASTRO) and the American Academy of Hospice and Palliative Medicine (AAHPM). However, there are differences in the treatment recommendations between these two specialty societies: ASTRO recommends regimens of 10 or fewer fractions for patients with advanced cancer and painful uncomplicated bone metastases, whereas AAHPM recommends a single-fraction regimen for these patients. ${ }^{11}$

A recent international survey of radiation oncologists showed that physicians in the United States have been slower to adopt single-fraction therapy compared with clinicians in other countries, even among patients who meet criteria of those included in the clinical trials demonstrating similar outcomes with abbreviated therapy. ${ }^{12-15}$ Although the evidence has grown for the use of fewer fractions in palliation of painful bone metastases in advanced cancer, there are several potential reasons that practice has not followed. First, the evidence for fewer fractions for uncomplicated metastases is not absolute for all patients. Despite the fact that there have been several randomized controlled trials (RCTs) and systematic reviews that conclude similar pain outcomes, there are higher retreatment rates (8\% vs. 20\%). ${ }^{16}$ Most of these studies have not considered quality of life as an outcome, ${ }^{12,13,15,17-22}$ and fee-for-service medicine incentivizes more treatments. Further complicating the issue, hypofractionated radiotherapy to the spinal region for metastatic disease (stereotactic body radiation treatment [SBRT]) is a new technology that appears to be at least as effective as standard multiple-fraction therapy, but it requires special training and preparation. ${ }^{23}$

To design an intervention to decrease fractionation schedules for appropriate patients presenting with painful bone metastases, we studied the range of practices considered appropriate for these patients by radiation oncologists at one academic medical center and evaluated current practices at the same institution.

\section{Methods \\ Defining uncomplicated bone metastases}

To define uncomplicated bone metastases for this quality improvement project, the randomized clinical trials identified as informative by the ASTRO literature review were evaluated for their inclusion and exclusion criteria $^{16}$ (Table 1). Based on these criteria, we preliminarily defined an uncomplicated bone metastases as one without pathological fracture, prior radiotherapy, or suspicion of spinal cord compression. Because there was no mention of tumor size or location in most studies, the working definition of uncomplicated metastases does not rely on these factors.

\section{Appropriateness of treatment plans}

Similar to the approach used to determine the American College of Radiology (ACR) appropriateness criteria, ${ }^{24,25}$ we used the modified RAND/UCLA appropriateness methodology to understand how radiation oncologists make decisions about single-fraction treatment. ${ }^{26}$ We constructed a survey instrument to elicit radiation oncologist practice patterns that included cases with uncomplicated bone metastases at four different locations (spine, humeral head, femur, rib) (Supplementary Data; Supplementary Data are available online at www.liebertpub.com/jpm). Eight radiation oncologists with varying sub-specialties were provided ASTRO guidelines, a summary table of the findings from RCTs referenced in the guidelines, and recent research on current practices. They rated the appropriateness of $8 \mathrm{~Gy}$ single-fraction treatment and four alternative regimens for the clinical case scenarios before and after a panel discussion that also included three palliative care physicians. Clinical cases varied by location of metastases, size of metastases, patient prognosis, travel distance to treatment site, and patient age. We also explored how treatment varied based on whether the patient had oligometastases. We report final median appropriateness ratings and a qualitative evaluation of discussion. 
Table 2. Median Appropriateness Ratings of Radiation Oncology Treatment Plans

\begin{tabular}{|c|c|c|c|c|c|}
\hline Case & $\begin{array}{l}8 G y \times 1 \\
\text { fraction } \\
\text { (Single } \\
\text { fraction) }\end{array}$ & $\begin{array}{l}\text { SRS with } \\
\text { ablative } \\
\text { dose }\end{array}$ & $\begin{array}{c}10 \text { fractions } \\
\text { of } 3 \\
G y=30 G y\end{array}$ & $\begin{array}{c}\text { Between } \\
1 \text { and } 10 \\
\text { fractions } \\
(4 \text { or } 5 \\
\text { fractions }=20 \mathrm{~Gy})\end{array}$ & $\begin{array}{c}>10 \\
\text { fractions }\end{array}$ \\
\hline \multicolumn{6}{|l|}{ Spine } \\
\hline General $^{\mathrm{a}}$ & 7 & 8 & 8 & 8.5 & 3 \\
\hline Large & 4 & 5 & 8 & 8 & 7 \\
\hline$<6$ months & 9 & 5.5 & 5 & 7.5 & 1 \\
\hline Lives $>2$ hours away & 8 & 8 & 4.5 & 7.5 & 1 \\
\hline Patient is 83 years old, not 63 & 8 & 7.5 & 6.5 & 7.5 & 1.5 \\
\hline Patient is 43 years old, not 63 & 7.5 & 8.5 & 7.5 & 8 & 5 \\
\hline \multicolumn{6}{|l|}{ Left humeral head (oligometastatic) } \\
\hline General $^{\mathrm{a}}$ & 8 & 2 & 8 & 8 & 4 \\
\hline Large & 7 & 1 & 8 & 8 & 3 \\
\hline$<6$ months & N/A & N/A & N/A & N/A & N/A \\
\hline Lives $>2$ hours away & 8.5 & 1.5 & 4 & 8 & 1 \\
\hline Patient is 83 , not 63 & 8 & 1.5 & 6 & 7.5 & 1.5 \\
\hline Patient is 43 , not 63 & 7.5 & 5 & 7.5 & 8 & 3 \\
\hline \multicolumn{6}{|c|}{ Left humeral head (widely metastatic) } \\
\hline General $^{\mathrm{a}}$ & 8.5 & 1 & 7 & 8 & 2 \\
\hline Large & 8 & 1 & 8 & 8 & 1.5 \\
\hline$<6$ months & 9 & 1 & 4.5 & 8 & 1 \\
\hline Lives $>2$ hours away & 9 & 1 & 3 & 8 & 1 \\
\hline Patient is 83 , not 63 & 9 & 1 & 5 & 8 & 1 \\
\hline Patient is 43 , not 63 & 8 & 1 & 7 & 8 & 2 \\
\hline \multicolumn{6}{|l|}{ Left femur (oligometastatic) } \\
\hline General $^{\mathrm{a}}$ & 7 & 6 & 7.5 & 7.5 & 3 \\
\hline Large & 6 & 2 & 8 & 8 & 3 \\
\hline$<6$ months & N/A & N/A & N/A & N/A & N/A \\
\hline Lives $>2$ hours away & 8 & 3.5 & 5 & 8 & 1 \\
\hline Patient is 83 , not 63 & 8 & 1 & 7 & 8 & 2.5 \\
\hline Patient is 43 , not 63 & 7.5 & 6 & 7 & 8 & 3 \\
\hline \multicolumn{6}{|l|}{ Left femur (widely metastatic) } \\
\hline General $^{\mathrm{a}}$ & 8.5 & 1 & 7 & 8 & 2 \\
\hline Large & 8 & 1 & 7.5 & 8 & 2.5 \\
\hline$<6$ months & 8.5 & 1 & 6.5 & 8 & 1.5 \\
\hline Lives $>2$ hours away & 9 & 1 & 3.5 & 8 & 1 \\
\hline Patient is 83 , not 63 & 9 & 1 & 6.5 & 8 & 1 \\
\hline Patient is 43 , not 63 & 7.5 & 1 & 6 & 8 & 2 \\
\hline \multicolumn{6}{|l|}{ Right rib (oligometastatic) } \\
\hline General $^{\mathrm{a}}$ & 7 & 7 & 7.5 & 8 & 3 \\
\hline Large & 6 & 3.5 & 8 & 8 & 2.5 \\
\hline$<6$ months & N/A & N/A & N/A & N/A & N/A \\
\hline Lives $>2$ hours away & 8 & 7 & 6.5 & 8 & 2 \\
\hline Patient is 83 , not 63 & 8 & 6.5 & 6 & 8 & 3 \\
\hline Patient is 43 , not 63 & 7.5 & 6.5 & 7 & 7.5 & 2 \\
\hline \multicolumn{6}{|l|}{ Right rib (widely metastatic) } \\
\hline $\mathrm{General}^{\mathrm{a}}$ & 8.5 & 1.5 & 7 & 8 & 2 \\
\hline Large & 7 & 1 & 7 & 8 & 2 \\
\hline$<6$ months & 8.5 & 1 & 5.5 & 8 & 1 \\
\hline Lives $>2$ hours away & 8 & 1 & 4 & 8 & 1.5 \\
\hline Patient is 83 , not 63 & 8 & 2 & 5.5 & 8 & 1 \\
\hline Patient is 43 , not 63 & 7.5 & 2.5 & 7 & 8 & 1 \\
\hline
\end{tabular}

Appropriateness ratings as follows: 1-3 inappropriate, 4-6 equivocal, 7-9 appropriate.

${ }^{\mathrm{a}}$ For general case, raters asked to assume that patient has a Karnofsky performance status of at least 80 and a prognosis of greater than six months. For all cases, raters asked to assume that there is no spinal cord compression (if spinal lesion), no prior irradiation, and no associated pathological fracture.

SRS, stereotactic radiosurgery. 


\section{Understanding current patterns of practice}

We conducted chart reviews for all patients seen by radiation oncology at one academic medical center between July 2012 and June 2013 with a visit ICD-9 diagnosis code of 198.5 to identify all patients seen during this period for an initial consult to treat painful bone metastases. We did not conduct chart abstractions on cases in which the patient did not receive radiation therapy after initial evaluation (due to either provider not recommending or patient declining/lack of follow-up/treatment elsewhere), only a follow-up visit for previous treatment fell within the study period, the lesion treated was not primarily a bone metastases (but may have involved bone), or there was no documentation of pain and the patient was treated for another reason (for example, disease control or to prevent fracture). The abstraction window began one year before the initial radiation consult and continued up to one year after the initial consult. Trained nurse abstractors used a detailed chart abstraction tool and guidelines to collect information about location of bone metastases, whether the metastases were complicated, and treatment regimens prescribed and received. They also collected patient demographics and documentation about prognosis and treatment preferences. We conducted dual chart abstraction for six of the charts and found $100 \%$ agreement for the reliability of abstraction of prior radiation, spinal cord compression, history of pathological fracture, number of fractions prescribed and completed, and type of radiation provided for each metastasis.

\section{Results}

\section{Appropriateness of treatment plans}

The panel demonstrated general agreement on the definition of an uncomplicated bone metastases as one without pathological fracture, prior radiotherapy, or suspicion of spinal cord compression. Radiation oncologist ratings of appropriateness of various treatment regimens for painful uncomplicated bone metastases varied by tumor site, tumor size, patient prognosis, patient age, and for nonspinal lesions whether the patient had oligometastases (Table 2). Single-fraction treatment (8 Gy) was rated as the most appropriate treatment, regardless of other factors, if prognosis was six months or less. Use of greater than 10 fractions was rated as inappropriate regardless of other factors with the exception of treatment for large spinal tumors. Older age and greater travel distance were associated with favoring $8 \mathrm{~Gy}$ single-fraction treatment. There was less consensus regarding whether single-fraction treatment was the most appropriate treatment for lesions located on the spine (especially large lesions), for patients with oligometastases, and for patients with a longer prognosis for whom goals may include local tumor control in addition to palliation. However, in most cases, regimens consisting of $<10$ fractions were considered more appropriate or at least equivalent to the 10 -fraction regimen.

\section{Current practice patterns}

Among the 172 patients identified with a documented radiation consult using the 198.5 diagnosis code, 84 had treatment initiated for painful bone metastases during the study period. We performed chart abstraction on the 81 patients who had a completed initial radiation oncology consult documented in the medical record.
The majority, 66 out of $81(81 \%)$, of the initial radiation oncology consults were seen in the outpatient setting, and a variety of cancers were represented (Table 3 ). Patients had a mean age of 61 years, and the majority were men $(62 \%)$, white $(64 \%)$, and married (59\%). These 81 patients had 107 different metastases treated ( $44 \%$ spine, $12 \%$ rib, $10 \%$ pelvis, $12 \%$ shoulder/arm, $8 \%$ hip/leg, $13 \%$ other). Sixty-nine percent of these metastases met our definition for being uncomplicated. Thirty-one percent of lesions were considered complicated because of one or more of the following issues: spinal cord compression $(13 \%)$, history of prior radiation to the same location (11\%), or an associated pathological fracture $(10 \%)$ (Table 4$)$.

The majority of metastases $(74 \%)$ were treated with conformal therapy, and 26\% were treated with SBRT. Among patients with uncomplicated bone metastases receiving conformal treatments, almost one-half received the most common treatment plan $(3 \mathrm{~Gy} \times 10$ fractions $)$ and one-third received greater than 10 fractions. One patient received single-fraction treatment with $8 \mathrm{~Gy}$, and $15 \%$ received four or five fractions. Most patients who received SBRT received their treatment in one dose 16/27 (59\%). There was no difference between practice patterns for complicated and uncomplicated metastases (Table 5).

Documentation of patient functional status occurred to some degree in most cases $(77 \%)$, but documentation of a

Table 3. Patient-Level Characteristics $(\mathrm{N}=81)$

Setting of initial radiation oncology consult

\begin{tabular}{|c|c|}
\hline Inpatient, $n(\%)$ & $14(17)$ \\
\hline Outpatient, $n(\%)$ & $66(81)$ \\
\hline Missing, $n(\%)$ & $1(2)$ \\
\hline \multicolumn{2}{|l|}{ Cancer type, $n(\%)$} \\
\hline Bladder & $1(1)$ \\
\hline Lung & $9(11)$ \\
\hline Breast & $19(23)$ \\
\hline Cervical & $2(2)$ \\
\hline Colorectal & $4(5)$ \\
\hline Head and neck & $1(1)$ \\
\hline Liver & $2(2)$ \\
\hline Lymphoma & $1(1)$ \\
\hline Melanoma & $2(2)$ \\
\hline Prostate & 15 (19) \\
\hline Renal & $5(6)$ \\
\hline Thyroid & $2(2)$ \\
\hline Unknown primary & $3(4)$ \\
\hline Other & $15(19)$ \\
\hline Age, mean (SD) & $61.1(17.2)$ \\
\hline \multicolumn{2}{|l|}{ Jender, $n(\%)$} \\
\hline Male & $50(62)$ \\
\hline Female & $31(38)$ \\
\hline \multicolumn{2}{|l|}{ ace, $n(\%)$} \\
\hline White & $52(64)$ \\
\hline African American & 7 (9) \\
\hline Asian & $7(9)$ \\
\hline Other & $2(3)$ \\
\hline No data & $13(16)$ \\
\hline \multicolumn{2}{|l|}{ Marital status, $n(\%)$} \\
\hline Married & $48(59)$ \\
\hline Lives with significant other & $1(1)$ \\
\hline Single/separated/divorced/widowed & $32(40)$ \\
\hline
\end{tabular}




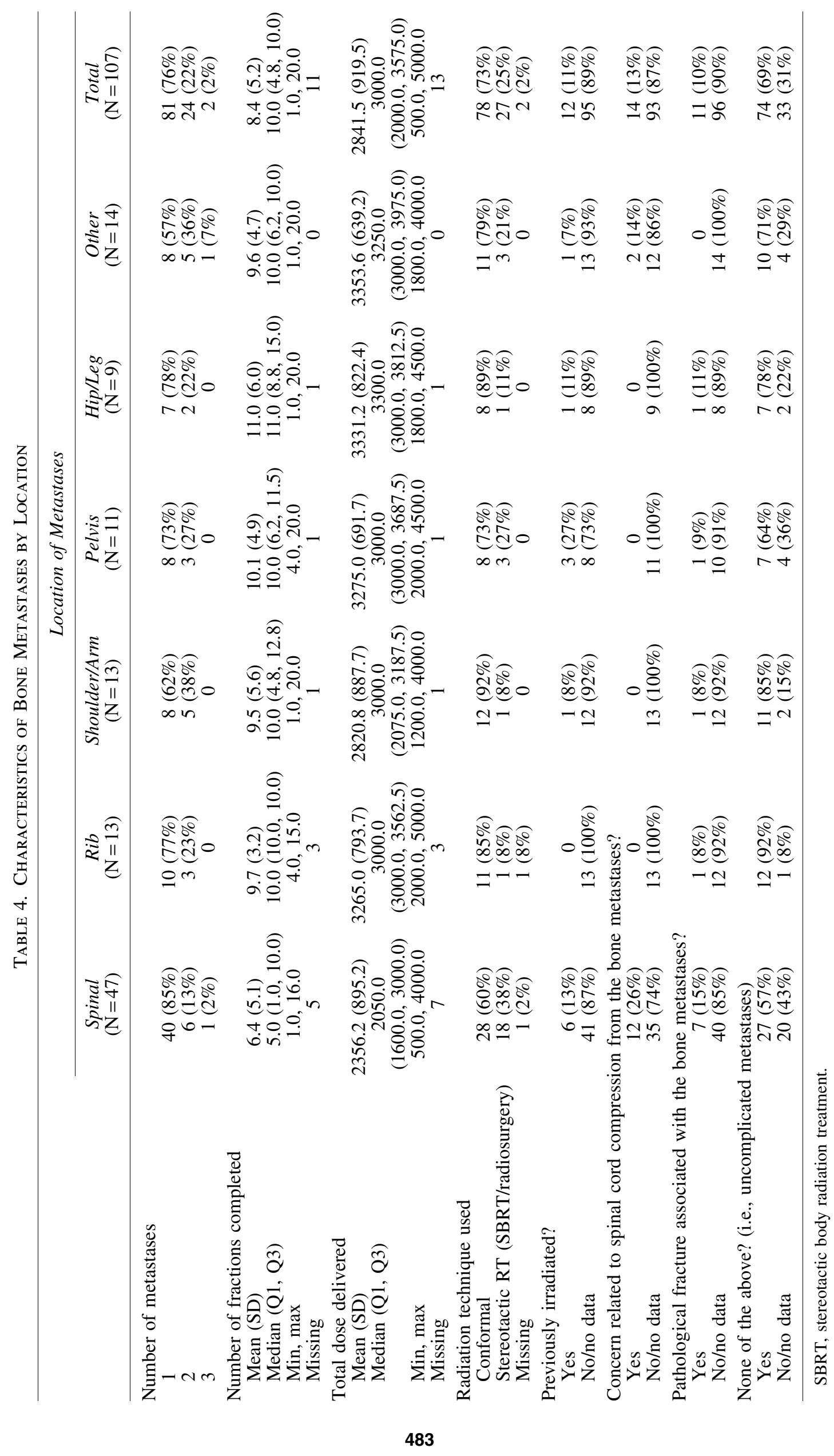


Table 5. Number of Prescribed and Completed Fractions Stratified by Type of Radiation and Whether the Bone Metastases Were Complicated or Uncomplicated

\begin{tabular}{|c|c|c|c|c|c|c|}
\hline & \multicolumn{3}{|c|}{ Conformal } & \multicolumn{3}{|c|}{ Stereotactic $R T$ (SBRT or radiosurgery) } \\
\hline & $\begin{array}{l}\text { Not complicated } \\
\quad(\mathrm{N}=54)\end{array}$ & $\begin{array}{l}\text { Complicated } \\
\qquad(\mathrm{N}=24)\end{array}$ & $\mathrm{p}$ & $\begin{array}{l}\text { Not complicated } \\
\quad(\mathrm{N}=18)\end{array}$ & $\begin{array}{l}\text { Complicated } \\
\qquad(\mathrm{N}=9)\end{array}$ & $\mathrm{p}$ \\
\hline \multicolumn{7}{|c|}{ Number of fractions prescribed (categorized) } \\
\hline 1 & $1(2 \%)$ & 0 & 0.811 & $11(61 \%)$ & $5(56 \%)$ & 1 \\
\hline $2-9$ & $9(17 \%)$ & $3(13 \%)$ & & $5(28 \%)$ & $3(33 \%)$ & \\
\hline 10 & $27(50 \%)$ & $14(58 \%)$ & & 0 & 0 & \\
\hline $10+$ & $15(28 \%)$ & $5(21 \%)$ & & 0 & 0 & \\
\hline Missing & $2(4 \%)$ & $2(8 \%)$ & & $2(11 \%)$ & $1(11 \%)$ & \\
\hline \multicolumn{7}{|c|}{ Number of fractions completed (categorized) } \\
\hline 1 & $1(2 \%)$ & 0 & 0.444 & $11(61 \%)$ & $5(56 \%)$ & 1 \\
\hline $2-9$ & $8(15 \%)$ & $7(29 \%)$ & & $5(28 \%)$ & $3(33 \%)$ & \\
\hline 10 & $24(44 \%)$ & $10(42 \%)$ & & 0 & 0 & \\
\hline $10+$ & $17(32 \%)$ & $5(21 \%)$ & & 0 & 0 & \\
\hline Missing & $4(7 \%)$ & $2(8 \%)$ & & $2(11 \%)$ & $1(11 \%)$ & \\
\hline
\end{tabular}

formal functional status scale occurred less commonly (Karnofsky Performance Status [KPS] documented for 35\% of patients and Eastern Cooperative Oncology Group [ECOG] score documented for $23 \%$ of patients). Documentation of patient prognosis $(2 \%)$, discussion regarding patient preferences regarding choices, options, or alternative radiation oncology regimens $(14 \%)$, travel distance $(10 \%)$ or length of regimen (4\%) rarely occurred during the initial radiation oncology consult. No patient was receiving hospice at the time of initial consult.

Thirteen of the 81 patients (16\%) died within six months of the radiation oncology initial consult, and three of these patients received hospice before death. Thirty-six percent of the treatments for these patients involved $>10$ fractions, and there was no statistically significant difference in practice patterns when comparing patients who lived less or more than six months. An additional 12 patients received hospice services within the year after initial radiation consult. Seventy percent of the patients were concurrently receiving chemotherapy or had received chemotherapy in the past 90 days. Receipt of chemotherapy was not significantly associated with a difference in the number of fractions used to treat painful bone metastases. Only $15 \%$ had decided to forgo further chemotherapy. Seventy-five percent of these patients (61/81) had documentation of a surrogate decision maker in the medical record, but only $19 \%(15 / 81)$ had an advance directive that identified patient preferences regarding life sustaining treatments. During the study period, prognosis or goals of care were considered and discussed for (51/81) $63 \%$ of patients.

\section{Discussion}

Although guidelines suggest that $<10$ fractions, or even single-fraction radiation, is an appropriate alternative to longer treatment plans for patients presenting with painful bone metastases ${ }^{16}$ and the radiation oncologists at the studied practice agreed with those guidelines, their practice did not routinely utilize shorter course treatments. Only one of the 74 uncomplicated bone metastases was treated with singlefraction conformal radiotherapy, and the most common treatment regimen was $3000 \mathrm{cGy}$ in 10 fractions. The low proportion of patients with metastatic bone disease receiving
$<10$ fractions of radiation found in our small study is consistent with others' findings. A recent published report showed that more than half of Medicare patients who received radiotherapy for painful bone metastases related to prostate cancer received $>10$ fractions and only $3.3 \%$ received single-fraction treatment. ${ }^{27} \mathrm{~A}$ recent study of a nationally representative sample of patients with metastatic nonsmall cell lung cancer showed that only $20 \%$ patients received five or fewer fractions and only $6 \%$ received singlefraction treatment. ${ }^{28}$ It should be noted that these studies do not distinguish between complicated and uncomplicated bone metastases. Although in our study there was no statistically significant difference in treatment patterns between the 1 out of 3 patients treated for complicated bone metastases compared with those treated for uncomplicated metastases, any evaluation of the best practice for this care process should make this distinction, because the RCTs supporting this practice exclude complicated metastases.

Furthermore, this study demonstrates that, from the perspective of both the selection criteria of the studies underlying the guidelines and also the views of radiation oncologists, decisions about numbers of fractions must account for patient prognosis and other patient factors. Although results of clinical trials suggest that single-fraction radiotherapy is equivalent to multiple-fraction radiotherapy in most scenarios, our study, consistent with ACR Appropriateness Criteria, suggests that there are circumstances in which multiple fractions may be more beneficial. ${ }^{24,25}$ For example, $31 \%$ of metastases in this study were classified as complicated (and, therefore, perhaps not appropriate for single-fraction therapy). Such clinically relevant considerations are not accounted for in many reports of the singlefraction radiation therapy quality gap. ${ }^{27,28}$

Reasons for quality problems in this area are complex, and high-quality supportive care, which requires communication and continuity of care across care settings and providers for seriously ill patients, is not incentivized by the fee-for-service healthcare system. ${ }^{29}$ A prior study showed that patients who received care in an integrated network tended to be treated with fewer fractions for metastatic bone lesions. $^{28}$ For patients with advanced cancer, tumordirected therapies and challenges with prognostication add 
to the complexity of providing high-quality patient-centered care. For example, the use of SBRT is an emerging pattern of practice ( $25 \%$ of metastases in our sample), especially for spinal metastases ${ }^{30}$ and is often delivered in a single dose, but requires a costly and complex planning process and execution.

Using a modified Delphi panel approach to clarify appropriate treatment provided a valuable mechanism for facilitating group involvement in quality improvement and also a comparison to current practices. An important result of our two-phase evaluation was the recognition that patient preferences for care and other patient factors (such as age and travel distance) that may affect a radiation oncologist's decision are often not discussed and documented in medical records. Quality improvement efforts must integrate a more patient-centered approach to treatment plans in this population. Earlier advance care planning and goals-of-care discussions are an important part of realizing this goal. In fact, a radiation oncology consult may serve as an opportunity to assess palliative care needs for this patient population that is known to benefit from early palliative care. ${ }^{5}$

Another key to improving practice is developing a common strategy toward handling bone metastases across a diverse practice. The large radiation oncology practice studied here treated only 84 cases for painful bone metastases during an entire year; thus, individual clinicians infrequently encounter bone metastases. Guiding practice at the point of care through a note template developed by the group will serve to guide best practices and facilitate data ascertainment for analysis and feedback.

In summary, choosing a radiation treatment schedule for patients with advanced cancer and painful bone metastases requires consideration of many medical and patientcentered factors. Administrative data do not allow for a full evaluation of the appropriateness of care. Our experience suggests that it will take more than the existence of guidelines to change practice in this area; quality improvement efforts are underway.

\section{Acknowledgments}

The authors acknowledge the significant contributions of the UCLA Radiation Oncology Quality Improvement for Patients with Painful Bone Metastases Panel, including P.J.B., T.K., and S.A.M.; C.R.K.; M.S., Percy Lee, MD, Steve Lee, MD, and Diana Gage, MD. They also acknowledge the contributions of David Wallenstein, MD, and Thomas Strouse, MD. Dr. A.M.W. was also supported by UCLA CTSI Grant Number UL1TR000124 and the NIH Loan Repayment Program.

\section{Author Disclosure Statement}

Dr. A.M.W. was supported by the NIH/National Center for Advancing Translational Science (NCATS) UCLA CTSI Grant Number (UL1TR000124) and the NIH loan repayment program. Dr. Walling is also supported by the Cambia Health Foundation Sojourns Scholar Leadership Program. Dr. A.M.W. has no other conflicts of interest to report. Dr. P.A.K. is a consultant for Varian Medical Systems, ViewRay, Siemens, and IBA. None of the other authors have conflicts to report. Preliminary data for this article were presented as a poster in October 2014 at the American Society for Clinical Oncology (ASCO) Palliative Care Symposium in October
2014 and the Annual Assembly for the American Academy of Hospice and Palliative Medicine (AAHPM) in February 2015.

\section{References}

1. Steinhauser KE, Christakis NA, Clipp EC, et al.: Factors considered important at end of life by patients, family, physicians and other care providers. JAMA 2000;284: 2476-2482.

2. Steinhauser KE, Christakis NA, Clipp EC, et al.: Preparing for the end of life: Preferences of patients, families, physicians, and other care providers. J Pain Symptom Manage 2001;22:727-737.

3. Wright AA, Zhang B, Ray A, et al.: Association between end-of-life discussions, patient mental health, medical care near death, and caregiver bereavement adjustment. JAMA 2008;300:1665-1673.

4. Lautrette A, Darmon M, Megerbane B, et al.: A communication strategy and brochure for relatives of patients dying in the ICU. N Eng J Med 2007;356:469.

5. Temel JS, Greer JA, Muzikansky A, et al.: Early palliative care in patients with metastatic non-small cell lung cancer. N Eng J Med 2010;363:733-742.

6. Wright AA, Keating NL, Balboni TA, et al.: Place of death: Correlations with quality of life of patient with cancer and predictors of bereaved caregivers' mental health. J Clin Oncol 2010;28:4457-4464.

7. Dy SM, Asch SM, Naeim A, et al.: Evidence-based standards for cancer pain management. J Clin Oncol 2008;26: 3879-3885.

8. Walling AM, Asch S, Lorenz K, et al.: The quality of care provided to hospitalized patients at the end of life. Arch Intern Med 2010;170:1057-1063.

9. Walling AM, Asch SM, Lorenz KA, et al.: The quality of supportive care among inpatients dying with advanced cancer. Supp Care Cancer 2012;20:2189-2194.

10. Malin JL, O'Neill SM, Asch SM, et al.: Quality of supportive care for patients with advanced cancer in a VA medical center. J Palliat Med 2011;14:573-577.

11. Choosing wisely: An initiative of the American Board of Internal Medicine. www.choosingwisely.org/clinician-lists (Last Accessed September 9, 2015).

12. Fairchild A, Barnes E, Ghosh S, et al.: International patterns of practice in palliative radiotherapy for painful bone metastases: Evidence based practice? Int J Radiat Oncol Biol Phys 2009;75:1281.

13. Wu JS, Wong R, Johnston M, et al.: Meta-analysis of dose fractionation radiotherapy trials for the palliation of painful bone metastases. Int J Radiat Oncol Biol Phys 2003;55: 594-605.

14. Chow E, Harris K, Fan G, et al.: Palliative radiotherapy trials for bone metastases: A systematic review. J Clinc Oncol 2007:25:1423-1436.

15. Sze WM, Shelley MD, Held I, et al.: Palliation of metastatic bone pain: Single fraction versus multifraction radiotherapy - A systematic review of randomized trials. Clin Oncol (R Coll Radiol) 2003;15:345-352.

16. Lutz S, Berk L, Chang E, et al.: Palliative radiotherapy for bone metastases: An ASTRO evidence-based guideline. Int J Radiation Oncology Biol Phys 2011;79:965-976.

17. Falkmer U, Jarhult J, Wersall P, et al.: A Systematic overview of radiation therapy effects in skeletal metastases. Acta Oncol 2003;42:620-633.

18. Wai MS, Mike $S$, Ines $H$, et al.: Palliation of metastatic bone pain: Single fraction versus multiple fraction 
radiotherapy $-\mathrm{A}$ systematic review of the randomized trials. Cochrane Database Syst Rev 2004;2:CD004721.

19. Lowblaw DA, Wu JS, Kirbride P, et al.: Pain flare in patients with bone metatsases after palliative radiotherapy: A nested randomized control trial, Support Care Cancer 2007;15:451-455.

20. Harstell WF, Scott CV, Bruner DW, et al.: Randomized trial of short versus long-course radiotherapy for palliation of painful bone metastases. J Natl Cancer Inst 2005;97: 798-804.

21. Kaasa S, Brenne E, Lund JA, et al.: Prospective randomized multicenter trial on single fraction radiotherapy $(8 \mathrm{~Gy} \times 1)$ versus multiple fractions $(3 \mathrm{~Gy} \times 10)$ in the treatment of painful bone metastases. Radiother Oncol 2006;79:278-284.

22. Wu JS, Wong RK, Lloyd ND, et al.: Radiotherapy fractionation for the palliation of uncomplicated painful bone metastases: An evidence-based practice guideline. BMC Cancer 2004;4:71.

23. Hall WA, Stapleford LF, Hadjipanayis CG, et al.: Stereotactic body radiosurgery for spinal metastatic disease: An evidencebased review. Int J Surg Oncol 2011;2011:979214.

24. Kim EY, Chapman TR, Ryu S, et al.: ACR Appropriateness Criteria non-spine bone metastases. J Palliat Med 2015;18: 11-17.

25. Expert Panel on Radiation Oncology-Bone Metastases, Lo SS, Lutz ST, Chang EL, et al. ACR Appropriateness Criteria spinal bone metastases. J Palliat Med 2013;16:9-19.

26. Skekelle P: The Appropriateness Method. Med Decis Making 2004;24:228-231.

27. Bekelman JE, Epstein AJ, Emanuel EJ: Single vs. multiple fraction radiotherapy for bone metastases from prostate cancer. JAMA 2013;310:1501-1502.

28. Chen AB, Cronin A, Weeks JC, et al.: Palliative radiation therapy practice in patients with metastatic non-small cell lung cancer: A Cancer Care Outcomes Research and Surveillance Consortium (CanCORS) Study. J Clin Oncol 2013;31:558-564.

29. Lievens Y, Van den Bogaert W, Rjnders A, et al.: Palliative radiotherapy practice within Western European countries: Impact of the radiotherapy financing system? Radiother Oncol 2000;56:289-295.

30. Moussazadeh N, Lis E, Katsoulakis E et al.: Five-year outcomes of high-dose single-fraction spinal stereotactic radiosurgery. Int J Radiat Oncol Biol Phys 2015;93: 361-367.

31. Jeremic B, Shibamoto Y, Acimovic L, et al.: A randomized trial of three single-dose radiation therapy regimens in the treatment of metastatic bone pain. Int J Radiat Oncol Biol Phys 1998;42:161-167.

32. Bone Trial Working Party. 8 Gy single fraction radiotherapy for the treatment of metastatic skeletal pain: Randomized comparison with a multifraction schedule over 12 months of patient follow-up. Radiother Oncol 1999;52: 111-121.

33. Roos D, Turner S, O'Brien P, et al.: Randomized trial of $8 \mathrm{~Gy}$ in 1 versus $20 \mathrm{~Gy}$ in 5 fractions of radiotherapy for neuropathic pain due to bone metastases (Trans-Tasman Radiation Oncology Group, TROG 96.05). Radiother Oncol 2005;75:54-63.

34. Hartsell W, Konski A, Scott C, et al.: Randomized Trial of Short course versus long-course radiotherapy for palliation of painful bone metastases. J Natl Cancer Inst 2005;97: 798-804.

35. Foro A, Fontanals A, Galcerán J,et al.: Randomized clinical trial with two palliative radiotherapy regimens in painful bone metastases: $30 \mathrm{~Gy}$ in 10 fractions compared with $8 \mathrm{~Gy}$ in single fraction. Radiother Oncol 2008;89:150-155.

36. Sande A, Ruenes R, Lund J,et al.: Long-term follow-up of cancer patients receiving radiotherapy for bone metastases: Results from a randomised multicentre trial. Radiother Oncol 2009;91:261-266.

37. Nielsen O, Bentzen S, Sandberg E, et al.: Randomized trial of single dose versus fractionated palliative radiotherapy of bone metastases. Radiother Oncol 1998;47:233-240.

38. Steenland E, Leer J, van Houwelingen H, et al.: The effect of a single fraction compared to multiple fractions on painful bone metastases: a global analysis of the Dutch Bone Metastasis Study. Radiother Oncol 1999;52:101-109.

Address correspondence to: Anne M. Walling, MD, PhD VA Greater Los Angeles Healthcare System 911 Broxton Avenue Los Angeles, CA 90049

E-mail: awalling@mednet.ucla.edu 